\title{
A New Perspective on the Prodromal Training Phase (PTP)Beyond Aviation
}

\author{
Tina Coclami, ${ }^{1 *}$ Captain Vasileios Kloudas ${ }^{2}$ \\ ${ }^{1}$ Psychopathology, V Lecturer in Aviation Psychology, City University of London, UK \\ ${ }^{2}$ Chief Pilot, Olympic Air, UK
}

\begin{abstract}
Prodromal Training Phase (PTP) is the early identification, of the special characteristics that each trainee pilot has, beyond what is on their CV. It is important to do this before or at the beginning of the trainingbecause these characteristics will determine how efficientthe process of learning will be. That is why this article describes PTP since it could also be used in other fields of training beyond aviation which was the domain for which it was initially developed. To make sure that trainees do not just learn theories but to be able to think out of the box and figure out what is wrong and fix it.
\end{abstract}

Keywords: PTP, Crew Training, Stress, Motivation, Memory

\section{Perspective}

The need to give the proper emphasis on the affective domain in pilot's training was explained in the 'instructor skills beyond telling'1 presentation at the Royal Aeronautical Society annual 'International Flight Crew Training Conference', in September 2019. In combination with the cognitive domain which is the straightforward acquisition of knowledge, the affective domain is essential since the trainee's emotions and interests act as a motivation to learn. In order to provide effective training in both domains, attention has to be paid to the identification of the main issues that need special attention, in the period at the beginning of the training. Thus, the psychologically-based aviation training approach $\mathrm{PTP}^{2}$ has been developed. Prodrome is derived from the Greek word prodromos, meaning "running before". ${ }^{3}$ Early signs or symptoms often indicate the onset of a disease before more diagnostically specific signs and symptoms develop.

In the PTP, instructors take into considerationthat new knowledge will 'stick' on aperson's existing personality traits. Thisis like the interaction of Biology (geneticpredisposition) and Environment (life eventsand experiences). This means that each student may process the same informationdifferently according totheir previous experience and personality traits. Thus, it isimportant to understandthe special characteristics each trainee has, such as background, expectations, false memories and personality as this, willdetermine how efficient the process of learning and knowledge transfer will be foreach student.

Instructors have to observe individual behaviors and detect student's abilities, before the training starts.How? First by reading their CV (even the name that they chose to give to their emails may signify something for examplewarrior1@hotmail.com). Then, by observing their behavior and identifying the following issues in 5 steps at the beginning of the training:

1. Stress vs. anxiety: Differentiate Stress (which is a normal response to something new and could even act as a motivation) from Anxiety symptoms thatmayact as an obstacle to learning.

2. Expectations: Determine students training expectationsin order to be able to assess needs and motivation. Just one question can give a lot of information. For example: 'Why are you coming now and not a year later or earlier to this training? in order to see the timing, the context in his life. Another question could be: 'What do you expect from this training? Your goals?' in order to realise the motivation levels, the goals they set for themselves and if they are specific enough to act as true motivators. Finally, 'What previous learning of yours would be

\begin{tabular}{|l|l|}
\hline Quick Response Code: & *Corresponding author: Tina Coclami, CPsycholAFBPsS, PhD Psychopathology, V Lecturer in \\
Aviation Psychology, City University of London, UK \\
Received: 30 March, 2021 & Published: 26 April, 2021 \\
& Citation: Tina C, Captain VK. A New Perspective on the Prodromal Training Phase (PTP)Be- \\
yond Aviation. J Psych Sci Res. 2021;1(1):1-2. DOI: 10.53902/JPSSR.2021.01.000504
\end{tabular}


helpfulin this training? to see what the student actually learned and how they use this knowledge.

3. Cultural and training background: To understand pilot's-trainees' cultural and training background. In which country did they complete their training since under certain political orcultural conditions people may become more suspicious than others. This does not mean that they are paranoid. They may just have different experiences and perceive the world accordingly.

4. Personality traits: The same personality trait can be used in a positive or negative way. It's typically good to be detail-oriented, even todouble-check but not to have the habit of repeated checking. To have enthusiasm which comes from inside a person and may act as a motive to learn but not to be impulsive. Thus, the key point for the instructor is to identify the main personality characteristics thatneed special attention, before the training starts. For example, dothey exhibit suspicious thinking? Misinterpret what other people say? Too much assertiveness? Do they confuse Assertiveness with Aggressiveness? Also, it is very important to distinguish and focus on what people can change. We can't change Personality, but the same personality traits can be used in a good or a bad way while Attitude can be changed through the way werespond or think in a particular situation through training, experience and observation. We can't change IQ but EQ can be changed.

5. False memories: A person's memory is highly susceptible to suggestions from conversations with other people or reading. Memorymay be surprisingly inaccurate, even though a person believes they can recall events as they really occurred. A false memory may promote memory error and interfere with the learning process. ${ }^{4,5}$

These are the PTP steps that could be used in any kind of training. To detect those special characteristics beyond just a CV.

\section{Acknowledgments}

None.

\section{Funding}

None.

\section{Conflicts of interest}

Author declares that there is no conflict of interest.

\section{References}

1. Coclami, Kloudas. Prodromal Training Phase (PTP)on Aviation. Royal Aeronautical Society Proceedings: International Flight Crew Training Conference 2019.

2. Kloudas, Coclami. Instructor skills beyond telling. Available at Proceedings: International Flight Crew Training Conference 2019.

3. Prodrome.

4. Loftus EF. Creating false memories. Sci Am. 1997;277:70-75.

5. Storbeck J, Clore GL. Affect influences false memories at encoding: evidence from recognition data. Emotion. 2011;11(4):981-989. 